\title{
Rare Case of Inflammatory Pseudotumour of Central Nervous System - A Case Report
}

\section{Siddharth Gautam*}

Department of Neurosurgery, Dr. R.N. Cooper Municipal General Hospital and HBT Medical College, Mumbai, India

*Corresponding Author: Siddharth Gautam, Department of Neurosurgery, Dr. R.N. Cooper Municipal General Hospital and HBT Medical College, Mumbai, India.
Received: July 25, 2020

Published: August 14, 2020

(C) All rights are reserved by Siddharth

Gautam.

\begin{abstract}
Inflammatory Pseudotumours (IPT) are mostly benign lesions, mimicking malignant lesions and affecting almost all organ systems and are characterised by fibrotic ground tissue and polyclonal mononuclear infiltrate on histopathology. It is a disease of unknown pathogenesis and the brain is a rare site of occurrence. Here we present one such case we operated recently in our department.
\end{abstract} Keywords: Inflammatory Pseudotumour (IPT); Mixed Spindle Cell Pseudotumor; Plasma Cell Granuloma

\section{Introduction}

Inflammatory Pseudotumour (IPT) is a rare nonneoplastic condition that usually involves the lung and orbit, but is known to affect almost all the organ systems. The term 'Inflammatory Pseudotumour' was coined by Umiker and Iverson in 1954, after finding out that the clinical and image findings mimicked that of a malignant lesion. The cause of IPT is unknown. It is characterised histologically by the presence of acute and chronic inflammatory cells with a variable fibrotic response. It is also called spindle cell Pseudotumor, plasma cell granuloma, inflammatory myofibroblastic tumor. The condition is rare in the brain and is usually an intracranial extension of an extracranial tumour arising from the orbit. Rarely, the condition is primarily intracranial or within spinal cord, affecting young men mostly.

\section{Case Report}

A 62 year old lady presented with complaints of headache on and off since 2 months which was insidious in onset, mild to moderate in intensity and more in the frontal region. The headache is not related to any particular time of the day and is relieved by taking rest and medications. Patient also gave history of visual disturbances since 1 month and history of 3 episodes of seizures in 20 days, with the last episode taking place 1 week ago, which starts in the right lower limb and then involved the right upper limb with turning of the face to the opposite side lasting for about 2 minutes without loss of consciousness, uprolling of eyes, drooling of saliva and any preceding aura. Patient is a known case of hypertension, hypothyroidism and coronary artery disease, on treatment. Neurological examination of the patient was normal. MRI Brain (Plain and Contrast) showed T1, T2 isointense lesion with surrounding oedema in the left high parietal region. Patient was started on anticonvulsants and other supportive therapy and planned for craniotomy and excision of the lesion.

Operative procedure: The surgery performed was left parietal craniotomy and excision of the lesion.

Under strict aseptic conditions, with patient in supine position, under general anaesthesia and with the head turned to the right side, slightly flexed and fixed with 3 pin Mayfield apparatus, concerned part was painted and draped. Hockey stick incision was made in the left parietal region and deepened in layers. Free flap craniotomy was performed. The dura was opened in $\mathrm{C}$ shaped fashion with the curvature towards the superior sagittal sinus. The lesion was found adherent to the overlying dura which was separated. The dura was hitched all around. A soft, moderately vascular, whitish tumour was visualised in the left high parietal cortex which was excised in toto with the help of bipolar cautery and CUSA, under microscope guidance. Thorough wash of the region with garamycin was given and lax duroplasty was performed. Complete haemostasis was achieved and a subgaleal drain was placed in situ. The wound was closed in layers. Patient withstood the procedure well and patient was haemodynamically stable at the time of shifting to the ICU for further management. Post operatively, the patient was 
treated with steroids, antibiotics, anticonvulsants, anti-oedema drugs and other supportive drugs. She had right upper limb weakness and was started on physiotherapy for the same. Post operative CT Brain (Plain and Contrast) showed complete excision of the lesion with post operative changes. Patient's condition gradually improved and she was discharged from the hospital after a few days.

\section{Histopathology report}

The excised lesion showed brain parenchyma with increased heterogenous distribution of varying population of lymphocytes, plasma cells, few binucleate forms, macrophages along with occasional neutrophils. Focal areas showed perivascular accentuation of lymphocytes along with proximal small calibre blood vessels with prominent endothelial cells. The background showed reactive gliosis without any necrosis or increased mitotic activity. These features were suggestive of an inflammatory pseudotumour.

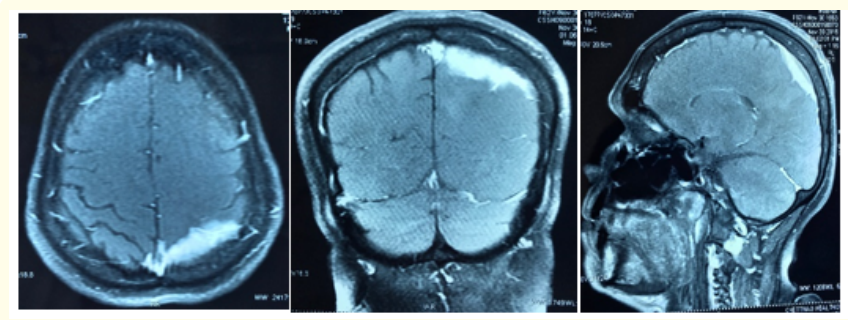

Figure 1: MRI brain plain and contrast showing an enplaque lesion in the left high parietal convexity abutting the occipital superior sagittal sinus without any mass effect or midline shift without any features of obstructive hydrocephalus.

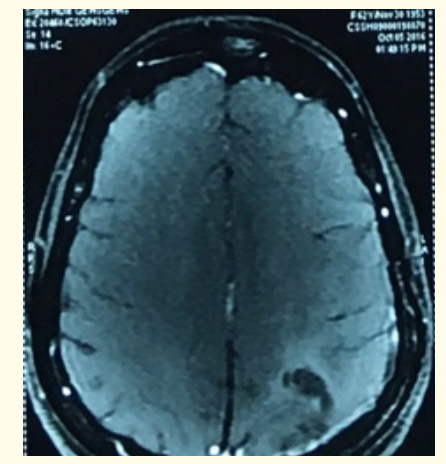

Figure 2: Post left high parietal craniotomy and excision of lesion showing complete excision of the lesion without any residual tumour with post operative changes without any evidence of post operative hematoma formation.

\section{Discussion}

Inflammatory Pseudotumour is a rare and benign chronic condition of unknown origin. It was first described by Birch-Hirschfield in 1905 for an orbital lesion and was so named by Umiker., et al. in 1954 because of its clinical and radiological similarity to a malignant lesion.

Inflammatory Pseudotumour of the head and neck region usually affect the orbit (orbital pseudotumour), orbital apex (orbital apex syndrome), superior orbital fissure (superior orbital fissure syndrome). Extraorbital sites include nasal cavity, nasopharynx, maxillary sinus, sphenoid sinus, infratemporal fossa, choroid plexus, larynx, trachea and skull bone. Extension into the brain parenchyma is rare.

IPT of the CNS is a rare and are usually seen in children and young adults. Patient usually either has no symptoms or presents with constitutional symptoms such as fever, weight loss and symptoms due to local mass effect from the lesion. In the brain, IPT is either found in the parenchyma, attached to the dura or both. MR Spectroscopy, in such patients, shows a lactate peak which suggests the presence of inflammation and hypoxia and an increase in the choline peak, which suggests increased cellularity and cell membrane synthesis due to inflammation.

Histopathology is necessary for a definitive diagnosis of inflammatory pseudotumour. Biopsy ideally shows nonspecific infiltration of inflammatory cells comprising of lymphocytes, plasma cells, neutrophils and macrophages. Due to the chronic nature of the condition, varying degrees of necrosis is seen. Variable giant cells, calcifications and circular fibrosis of the small veins is also seen.

Steroids and surgical resection are the modalities of treatment for inflammatory pseudotumour of the head and neck. If the tumour is resectable, complete excision is the preferred treatment of choice [1-6].

\section{Conclusion}

Inflammatory Pseudotumour is a rare entity. In this too, inflammatory pseudotumour of the brain is even more rare. There are not many reported cases of Inflammatory Pseudotumour of the brain in literature. It should be considered as one of the differential diagnosis of soft tissue malignant lesions of the brain. Histopathological diagnosis is a must and a confirmative diagnosis cannot be made based only on the clinical and radiological findings. Here we present one such case of Inflammatory Pseudotumour of the Left high parietal cortex. 


\section{Declaration of Patient Consent}

The author certifies that they have obtained all appropriate patient consent forms. In the form, the patient has given his consent for his images and other clinical information to be reported in the journal. The patient understands that his particulars will not be published and all due efforts will be made to conceal his identity, but anonymity cannot be guaranteed.

\section{Financial Support and Sponsorship}

Nil.

\section{Conflict of Interest}

There are no conflict of interest.

\section{Bibliography}

1. S De Vuysere., et al. "Extraorbital inflammatory pseudotumor of the head and neck: CT and MR findings in three patients". American Journal of Neuroradiology 20.6 (1999): 1133-1139.

2. LD Narla., et al. "Inflammatory pseudotumor". Radiographics 23.3 (2003): 719-729.

3. AM McKinney., et al. "Inflammatory myofibroblastic tumor of the orbit with associated enhancement of the meninges and multiple cranial nerves". American Journal of Neuroradiology 27.10 (2006): 2217-2220.

4. Madhavi Patnana., et al. "Inflammatory Pseudotumour: The Great Mimicker". American Journal of Roentgeneology 198.3 (2012).

5. Hedlund GL., et al. "Aggressive manifestations of inflammatory pulmonary pseudotumor in children". Pediatric Radiology 29 (1999): 112-116.

6. Coffin CM., et al. "Extrapulmonary inflammatory myofibroblastic tumor (inflammatory pseudotumor): a clinicopathologic and immunohistochemical study of 84 cases". American Journal of Surgery and Pathology 19 (1995): 859-872.

\section{Assets from publication with us}

- Prompt Acknowledgement after receiving the article

- Thorough Double blinded peer review

- Rapid Publication

- Issue of Publication Certificate

- High visibility of your Published work

Website: www.actascientific.com/

Submit Article: www.actascientific.com/submission.php Email us: editor@actascientific.com

Contact us: +919182824667 